work and of the desirability that adequate financial support should enable it to make its full contribution in assisting scientific co-operation and understanding.

\section{The Parapsychological Association}

THe formation of the Parapsychological Association, an international professional group of research workers in the field of extresensory perception and psychokinesis, has been announced. The objects of the Association are to advance parapsychology as a science, to disseminate knowledge of the field, and to integrate the findings with those of other branches of science. Full membership is restricted to those with doctorate degree training or equivalent. The founding officers are: President, R. A. McConnell (Biophysics Department, University of Pittsburgh); Vice-President, G. R. Schmeidler (Psychology Depertment, City College of New York); Secretary, R. White (Parapsychology Laboratory, Duke University); Treasurer, R. J. Cadoret (Duke University); Members of Council, M. Anderson (Duke University), K. Osis (Parapsychology Foundation of New York) and W. G. Roll (University of Oxford).

\section{Conference on High Energy Nuclear Physics}

MoRe than 200 scientiats from twenty-six nations have been invited to participate in the 1958 Annues International Conference on High Energy Physics, organized by the European Organization for Nuclear Research (CERN), in Geneva during June 30-July 5. Participation at the 1958 Conference is by invitation only. Among the 226 scientists invited so far, more than a hundred have already accepted, among them: Prof. W. Heisenberg, of Germany ; Prof. LeprinceRinguet, of France; Prof. E. Amaldi, of Italy; Prof. Hideki Yukawa, of Japan; Prof. P. Scherrer and Prof. W. Pauli, of Switzerland; Sir John Cockcroft and Prof. P. M. S. Bleckett, of the United Kingdom; and from the United States, Dr. C. N. Yang, Dr. T. D. Lee, Dr. J. R. Oppenheimer and Prof. L. W. Alvarez. During ten plenary sessions in the auditorium of the Physics Institute of the University of Geneva, papers will be presented on nucleon structure; the nucleon and its interactions with pions, photons, nucleons and anti-nucleons ; fundamental theoretical ideas; strange particle production and interaction; invariance principles and selection rules, and weak interactions. The conference proceedings, including original papers presented, will be published by CERN.

\section{Second Geneva Conference on Peaceful Uses of Atomic Energy}

Tre second International Conference on the Peaceful Uses of Atomic Energy is to be held in Geneva during September 1-13, under the auspices of the United Nations (Nature, 180, 217; 1957). The president of the Conference is to be Prof. F. Perrin, of the Commissariat aे l'Energie Atomique de France, and the secretary-general, Dr. S. Eklund, of Sweden. Two atomic energy exhibitions will be held in Geneva during the Conference. The first will be a scientific exhibition under the auspices of the United Nations, at the Palais des Nations. A United Kingdom exhibit, 5,000 sq. ft. in extent, is being arranged by the U.K. Atomic Energy Authority, to include a model of the thermonuclear research apparatus, ZETA. The other exhibition, which will be commercial, is the International Exhibition on the Peaceful Uses of Atomic Energy, at the Palais des
Expositions. The British section is being organized by the Nuclear Energy Trade Associations' Conference, which represents all major British firms concerned with atomic energy. People interested in attending the Conference as observers should apply for passes not later than April 19. Representatives from industrial firms who are working in the atomic energy field should apply to Mr. M. H. L. Whitehouse, Nuclear Energy Trade Associations' Conference, 32 Victoria Street, London, S.W.1, and all others to Mr. J. C. Walker, United Kingdom Atomic Energy Authority, 11 Charles II Street, London, S.W.1. The United Kingdom representatives on the United Nations scientific secretariat for the Conference will be Mr. F. Hudswell and Mr. W. B. Woollen (Atomic Energy Research Establishment, Harwell) and Mr. T. E. F. Carr (Medical Research Council).

\section{Isotope Courses at Harwell}

A COURse on radioisotopes, designed to give senior executives in industry an appreciation of the possible applications of those materials, will be held at the Harwell Isotope School during September 23-26. Two similar courses have been arranged for April 15-18 and July 8-11 for members of the Institute of Directors only. The course consists of lectures on the elementary principles of work with radioactive isotopes with the emphasis on their application as tools in industry and research. The lectures will be given in as non-technical a manner as possible by scientists experienced in the field; they will be supplemented by visits to a reactor and to the laboratories of the Isotope Division at Harwell and at the Wantage Radiation Laboratory near Harwell. The lectures and demonstrations will be given in the Cockcroft Hall at Harwell. Further information can be obtained from the Registrar, Isotope School, Atomic Energy Research Establishment, Harwell.

\section{City and Guilds of London Institute : Fellowships}

THE Council of the City and Guilds of London Institute have conferred the Fellowship of the Institute (F.C.G.I.) upon the following past students of the City and Guilds College or Finsbury Technical College in recognition of their distinguished con. tributions to industry or the professions in which they are engaged: D. H. Alexander, principal, College of Technology, Belfast; W. A. Coates, retired, former director of Metropolitan-Vickers Electrical Co., Ltd. ; G. H. Hopewell, managing director, Foster Whoeler, Ltd.; F. C. Wright, managing director, Standard Telephones and Cables, Ltd.

\section{The Night Sky in April}

Fund moon occurs on April 4d. 03h. 45m. U.T., and new moon on April 10d. 03h. 23m. The following conjunctions with the Moon take place: April 5d. 04h., Jupiter $2^{\circ}$ N.; April 9d. 02h., Saturn $3^{\circ}$ S. ; April 13d. 13h., Mars $7^{\circ}$ S. ; April 15d. 00h., Venus $4^{\circ} \mathrm{S}$. There will be an annular eclipse of the Sun on April 19, invisible at Greenwich. Mercury is favour. ably placed for observation during the first week of the month, setting at 20h. $20 \mathrm{~m}$. on April 1 ; its stellar magnitude on that date is $+0 \cdot 5$. Later in the month, Mercury is too close to the Sun for observation. Venus is a morning star, visible low in the south-east before sunrise. It rises at $4 \mathrm{~h} .10 \mathrm{~m}$., $3 \mathrm{~h} .50 \mathrm{~m}$. and $3 \mathrm{~h}$. $25 \mathrm{~m}$. on April 1, 15 and 30, respectively ; its stellar megnitude is about $-4 \cdot 0$. During 